\title{
Adenine Nucleotide Pools During Starvation of Beneckea natriegens
}

\author{
By NAHEED NAZLY, IAN S. CARTER† AND \\ CHRISTOPHER J. KNOWLES* \\ Biological Laboratory, University of Kent, Canterbury CT2 $7 \mathrm{NJ}$
}

(Received 13 June 1979)

\begin{abstract}
The marine bacterium Beneckea natriegens was grown in batch culture on a glucose/ $\mathrm{NH}_{4}{ }^{+}$/salts medium; growth terminated due to either carbon or nitrogen depletion from the medium. Nitrogen-limited cultures converted part of the excess glucose into glycogen whereas the carbon-limited cultures formed little glycogen. Glycogen-rich cultures survived longer than glycogen-poor cultures during starvation. Little protein was utilized during starvation and RNA was degraded as the primary endogenous source of energy. Glycogen was consumed only when the RNA content had decreased to about a third of the growth value.

The adenine nucleotide content of nitrogen-limited cultures increased at the start of the stationary phase but the energy charge remained at the growth value of 0.9 to 0.95 . The maximum size of the adenine nucleotide pool depended on the concentration of glucose remaining in the medium at the start of the stationary phase but a limiting value of about $60 \mu \mathrm{mol}$ ATP (g protein) ${ }^{-1}$ was attained, compared with 12 to $14 \mu \mathrm{mol}$ ATP (g protein) ${ }^{-1}$ in exponentially growing cultures. During extended starvation of both glycogen-rich and glycogen-poor cultures, there was a large decrease in adenine nucleotide content, but the energy charge remained above 0.6 even when viability was very low.
\end{abstract}

\section{INTRODUCTION}

There are many factors that can cause loss of viability of bacteria (Dawes, 1976). During long-term starvation, endogenous metabolites such as non-essential RNA, protein and reserve polymers (glycogen, poly- $\beta$-hydroxybutyrate, triacylglycerols and polyphosphate) act as energy sources permitting essential maintenance processes to occur, thereby preserving viability (Dawes \& Senior, 1973). Under these circumstances loss of viability may be related to the inability to regenerate ATP due to depletion of endogenous metabolites and reserve polymers. This would be seen as a decrease in the adenine nucleotide content or as a decrease in the ATP:ADP and ATP:AMP ratios, which may be measured as a decrease in energy charge (Atkinson, 1968, 1978; Chapman \& Atkinson, 1977; Knowles, 1977, 1979).

There have been few studies on the adenylate pools of starving bacteria. Chapman et al. (1971) showed that, following nitrogen depletion from a glucose-containing growth medium, there was a gradual decrease in the intracellular energy charge of Escherichia coli strain B from a growth value of about 0.8 to between 0.6 and 0.5 after 60 to $80 \mathrm{~h}$, without loss of viability. The intracellular adenine nucleotide content also decreased during this period. After 60 to $80 \mathrm{~h}$, a rapid decrease in energy charge occurred, coincident with a loss of viability. Montague \& Dawes (1974) showed a similar relationship of decrease in energy charge and loss of viability during starvation of Peptococcus prévotii, which does not form reserve polymers but utilizes RNA as the sole endogenous source of energy.

$\dagger$ Present address: The College of the Resurrection, Mirfield, West Yorkshire WF14 0BN. 0022-1287/80/0000-8805\$02.00 (C) 1980 SGM 
The effect of termination of growth on the adenine nucleotide composition of batch cultures, due to depletion of carbon or $\mathrm{NH}_{4}{ }^{+}$from the medium, has been examined in E. coli strain B (Chapman et al., 1971; Walker-Simmons \& Atkinson, 1977) and Beneckea natriegens (Niven et al., 1977a). (For simplicity, we will refer to these as 'carbon-limited' and 'nitrogen-limited' cultures.) Considerable differences are observed in maintenance of the adenylate pools of these two bacteria following the transition from exponential growth into the stationary phase. These effects have been reviewed by Knowles (1979).

Chapman et al. (1971) reported that the adenylate pool of $E$. coli strain B fell by $50 \%$ following glucose-limitation and the energy charge decreased from 0.8 to $0 \cdot 6$. The energy charge values were later revised to 0.9 to 0.93 and 0.9 to 0.8 , respectively (Walker-Simmons \& Atkinson, 1977). The latter energy charge value was maintained for 5 to $7 \mathrm{~h}$ until the acetate, which had been formed during the growth on glucose, had been utilized. The energy charge then gradually decreased. In succinate-limited cultures, the energy charge immediately dropped to 0.6 at the start of the stationary phase (Andersen \& von Meyenburg, 1977). In contrast to these results, glucose- or succinate-limitation of $B$. natriegens did not cause a measurable decrease in energy charge and there was a slight increase in the adenylate pool size (Niven et al., 1977a). During growth on glucose, but not on succinate, volatile acids were produced. They were consumed during a second, post-growth respiratory phase. The energy charge was maintained at 0.9 to 0.95 for at least $3 \mathrm{~h}$ after their oxidation.

Ammonia-limitation of glucose-grown cultures of E. coli strain B (Chapman et al., 1971; Walker-Simmons \& Atkinson, 1977) and B. natriegens (Niven et al., 1977a) also resulted in different responses of the adenine nucleotide pools. In both bacteria the energy charge was maintained at the growth value, but in $E$. coli the adenylate pool size remained stable whereas in $B$. natriegens it increased until the excess glucose had been oxidized. In both bacteria some of the excess glucose was deposited as glycogen. It has been suggested that deposition of glycogen by $E$. coli strain $\mathrm{W} 4597(\mathrm{~K})$ is due to a small rise in energy charge at the start of the stationary phase (Dietzler et al., 1974).

In view of the paucity of information about the adenine nucleotide composition of bacteria subjected to extended starvation, and the differences observed in adenylate pool maintenance at the start of the stationary phase in E. coli and B. natriegens, we have investigated these effects in starved $B$. natriegens.

\section{METHODS}

Organism and medium. Beneckea natriegens strain III (Baumann et al., 1971) was grown in the synthetic medium described previously (Niven et al., 1977a) but buffered with $100 \mathrm{~mm}$-Tris/HCl. For carbonlimited growth, $5 \mathrm{~mm}$-glucose and $25 \mathrm{~mm}-\mathrm{NH}_{4} \mathrm{Cl}$ were added; for nitrogen-limited growth, $8 \mathrm{~mm}$-glucose

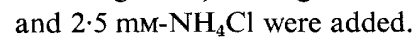

Growth of bacteria. The bacterium was maintained on agar slants (Difco Bacto marine agar 2216) with monthly subculturing. Bacteria for inocula were grown in $100 \mathrm{ml}$ medium in $250 \mathrm{ml}$ conical flasks for $16 \mathrm{~h}$ at $35^{\circ} \mathrm{C}$ on a rotary shaker $\left(200 \mathrm{rev} . \mathrm{min}^{-1}\right) ; 20 \mathrm{ml}$ of an appropriate culture was used to inoculate 11 of the experimental culture which was grown at $35^{\circ} \mathrm{C}$ in a 11 Quickfit fermentation vessel with a sampling/injection port, as described by Niven et al. (1977a). The air flow rate was $1.251 \mathrm{~min}^{-1}$ and the stirring rate was 10 cycles s $^{-1}$. During growth in the fermenter, bacteria were monitored daily for purity by microscopic examination, Gram staining, the ability to ferment rhamnose on an eosin methylene blue plate, citrate utilization and for the presence of catalase and Kovac's oxidase (Baumann et al., 1971).

Estimation of adenylates and energy charge. Culture samples $(0.8 \mathrm{ml})$ were collected rapidly into $0.2 \mathrm{ml}$ $25 \%(\mathrm{w} / \mathrm{v}) \mathrm{HClO}_{4}$ precooled to $4{ }^{\circ} \mathrm{C}$ in a spring-loaded syringe unit (Niven et al., 1977a). The supernatants from filtration $(0.45 \mu \mathrm{m}$ pore size filters) were also analysed. The luciferase assay procedure for analysis of ATP, ADP and AMP was used (Niven et al., 1977a). Poole \& Salmon (1978) reported interference of traces of $\mathrm{HClO}_{4}$ with the enzymic conversion of ADP and AMP to ATP. Our control experiments did not reveal similar difficulties, and there was no detectable interference.

Determination of glucose and glycogen. Glycogen was extracted by a modified Pflüger procedure (Hassid \& Abraham, 1957). To a $1.5 \mathrm{ml}$ cell sample, $0.75 \mathrm{ml} 90 \%$ (w/v) $\mathrm{KOH}$ was added, followed by digestion by heating in a boiling water bath for $15 \mathrm{~min}$. After cooling, $0.23 \mathrm{ml} 8 \%(\mathrm{w} / \mathrm{v}) \mathrm{Na}_{2} \mathrm{SO}_{4}$ and $5.8 \mathrm{ml}$ absolute 
ethanol were added. The precipitated glycogen was centrifuged and stored at $-22{ }^{\circ} \mathrm{C}$. This glycogen was dissolved in $1 \mathrm{ml}$ distilled water, re-precipitated with $2.4 \mathrm{ml}$ absolute ethanol and re-washed twice with water and ethanol. After hydrolysis in $0.5 \mathrm{ml} 1 \mathrm{M}-\mathrm{H}_{2} \mathrm{SO}_{4}$ at $100{ }^{\circ} \mathrm{C}$ for $3 \mathrm{~h}$ and subsequent neutralization to $\mathrm{pH} 7.0$ with $6 \mathrm{M}-\mathrm{NaOH}$, the liberated glucose was determined by the glucose oxidase method (Niven et al., 1977a).

Total cell numbers. Bacteria were killed by adding 1 drop of formaldehyde per $\mathrm{ml}$ to a $1: 10$ dilution of the culture in fresh medium. A drop of the suspension was placed on the grating of a haemocytometer (Improved Neubauer, B.S.748, depth $0.1 \mathrm{~mm}, 1 / 400 \mathrm{~mm}^{2}$; Weber \& Sons, Lancing, W. Sussex) and the coverslip was pressed down until Newton's rings were obtained. Eighty squares were counted using a Zeiss phase contrast microscope $(500 \times$ magnification).

Viable cell numbers. Cells were serially diluted in fresh culture medium without glucose. To avoid cold shock, the dilution tubes were preincubated at $35^{\circ} \mathrm{C}$ for $30 \mathrm{~min}$. Quintuplicate portions $(0.1 \mathrm{ml})$ of two appropriate dilutions were spread evenly over the surface of marine agar plates which had been dried at $35^{\circ} \mathrm{C}$ for $3 \mathrm{~h}$. The plates were incubated for $24 \mathrm{~h}$ at $35^{\circ} \mathrm{C}$ and colonies were then counted.

Viability. The percentage viability of cultures was estimated by a slide culture method similar to that of Postgate et al. (1961). Stainless-steel annuli on glass microscope slides were filled with marine agar from which solid debris had been removed and placed in Petri dishes containing fresh marine agar to keep the slides moist. Culture samples were diluted 10-fold, spread in duplicate on the surface of the agar film and excess fluid was removed with a Pasteur pipette. Coverslips were omitted and the cultures were incubated at $35^{\circ} \mathrm{C}$ for $90 \mathrm{~min}$ and inspected using a Zeiss phase contrast microscope $(500 \times$ magnification).

Measurement of RNA. A $10 \mathrm{ml}$ sample was removed from the fermentation vessel and centrifuged at $3000 \mathrm{~g}$ for $20 \mathrm{~min}$. The pellet was stored at $-22{ }^{\circ} \mathrm{C}$ until required. RNA was extracted as described by Blobel \& Potter (1968) and measured by the orcinol method (Herbert et al., 1971), using D-ribose as the standard. The RNA content was calculated using a correction factor of $4 \cdot 28$, assuming equal concentrations of each of the nucleotides.

Other assays. For protein determination, a $2 \mathrm{ml}$ sample from the fermentation vessel was centrifuged at $3000 \mathrm{~g}$ for $20 \mathrm{~min}$, and the pellet was resuspended in $2 \mathrm{ml} 5 \mathrm{M}-\mathrm{NaOH}$ and boiled for $2 \mathrm{~min}$; protein was assayed by the method of Lowry. Growth was monitored by the absorbance at $680 \mathrm{~nm}$, using $1 \mathrm{~cm}$ cuvettes in a Pye Unicam SP500 spectrophotometer. Poly- $\beta$-hydroxybutyrate was estimated by the method of Carter \& Dawes (1979), using a $5 \mathrm{ml}$ culture sample. For estimation of polyphosphate, a complete 11 culture was centrifuged, polyphosphate was extracted and hydrolysed as described by Herbert et al. (1971), and the phosphate released was estimated by the method of Fiske \& Subbarow (1925).

Chemicals. Adenylate kinase, firefly lantern extract (FLE-250), glucose oxidase, glyceraldehyde-3-phosphate dehydrogenase, 3-phosphoglycerate phosphokinase, ATP, ADP, AMP, NADP (grade III), phosphoenolpyruvate, glycylglycine and Tris (Trizma base) were obtained from Sigma. Pyruvate kinase [as an $\left(\mathrm{NH}_{4}\right)_{2} \mathrm{SO}_{4}$ suspension] was obtained from Boehringer. Whenever possible, all other reagents were of analytical grade; glass-distilled water was used throughout.

\section{RESULTS}

Figure 1 shows the effect of extended starvation on cultures of B. natriegens in which growth had terminated due to depletion of glucose from the medium. Growth, as measured by the absorbance and protein content of the culture, finished about $3 \mathrm{~h}$ after inoculation, when glucose was no longer detectable in the medium (Fig. 1a). During growth there was a high level of respiratory activity. Following glucose depletion there was a second respiratory phase of $2 \mathrm{~h}$ due to oxidation of excreted organic acids (not shown), in agreement with previous observations (Niven et al., 1977a), before oxygen uptake declined to a low level. The $\mathrm{pH}$ was between 7.2 and 7.5 throughout the experiment.

Total and viable cell numbers continued to increase (by about $50 \%$ ) after the maximum absorbance had been attained, indicating that a round of division continued after termination of growth (Fig. $1 \mathrm{~b}$ ). Viability remained at 90 to $100 \%$ for $22 \mathrm{~h}$, then declined rapidly. However, the total cell numbers remained high for at least $50 \mathrm{~h}$, indicating that loss of viability was not associated with cell lysis. The apparent fourfold discrepancy in total and viable cell numbers was due to a systematic error in the former counts. There was an increase in the thickness of the haemocytometer (Mallette, 1969). Also, there was probably incomplete division of cells seen under the phase contrast microscope, so that a single colony on a plate may have represented two undivided but viable cells. 


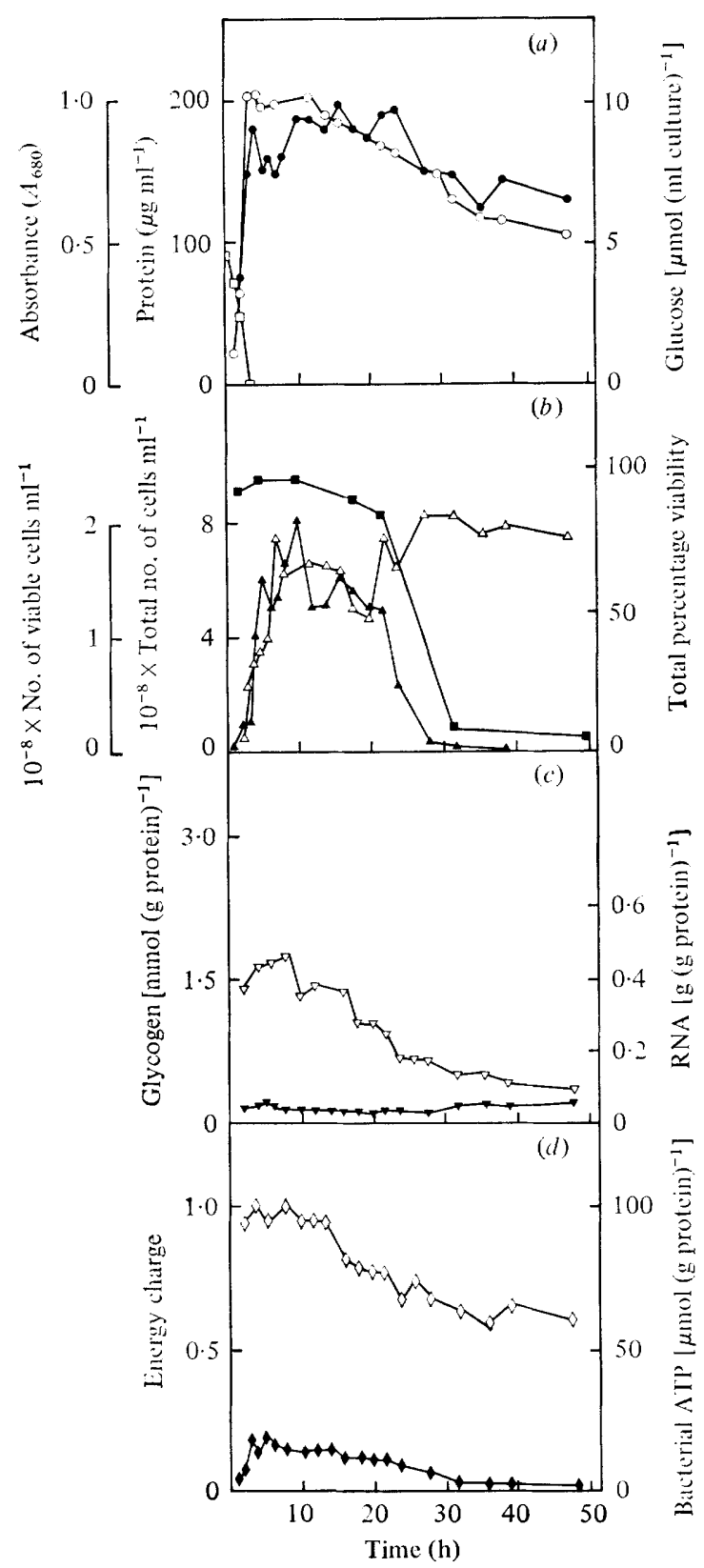

Fig. 1. Growth and starvation of $B$. natriegens under conditions where growth terminated due to depletion of glucose from the medium. The initial glucose and ammonium concentrations were $5 \mathrm{~mm}$ and $25 \mathrm{~mm}$, respectively. Absorbance ( $\bigcirc)$, protein (O), glucose $(\square)$, percentage viability $(\boldsymbol{\square})$, total cell numbers $(\triangle)$, viable cell numbers $(\boldsymbol{\Delta})$, RNA $(\nabla)$, glycogen, expressed in terms of its glucose content $(\boldsymbol{\nabla})$, energy charge $(\diamond)$, bacterial ATP $(\diamond)$.

Little glycogen was formed in carbon-limited cells (Fig. 1c). The RNA content decreased gradually during starvation, to about one-third of the optimum level at $22 \mathrm{~h}$ after inoculation, when viability started to decrease. Thereafter there was little change in RNA content. The protein content of the culture decreased only slightly during starvation for up to $50 \mathrm{~h}$ (Fig. 1a). 


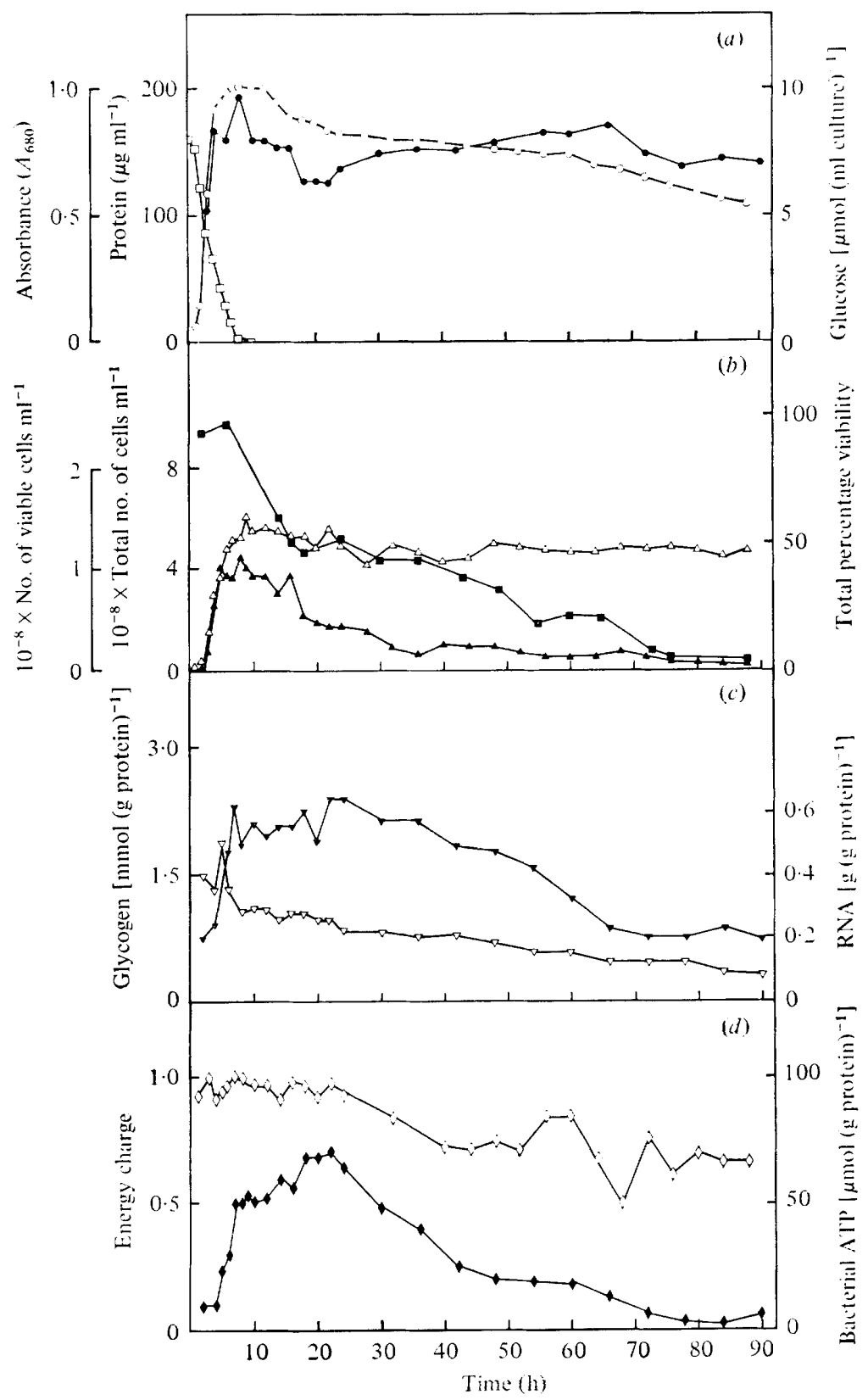

Fig. 2. Growth and starvation of $B$. natriegens under conditions where growth terminated due to depletion of ammonia from the medium. The initial glucose and ammonium concentrations were $8 \mathrm{~mm}$ and $2 \cdot 5 \mathrm{~mm}$, respectively. Symbols as in Fig. 1 .

During growth, the ATP content was about $14 \mu \mathrm{mol}$ (g protein) ${ }^{-1}$, equivalent to approximately $7 \mathrm{nmol}$ (mg dry wt) ${ }^{-1}$, in reasonable agreement with Niven et al. (1977 a). Following termination of growth, the ATP pool increased slightly and then declined gradually from $13 \mathrm{~h}$ after inoculation (Fig. $1 d$ ). The energy charge was about 0.95 during growth and decreased slowly from $13 \mathrm{~h}$ onwards, but was still 0.6 at $50 \mathrm{~h}$ when the total adenylate content was less than $10 \%$ of the maximum level and viability was only $6 \%$.

When $B$. natriegens was grown in a medium containing $8 \mathrm{~mm}$-glucose and $2.5 \mathrm{~mm}-$ 


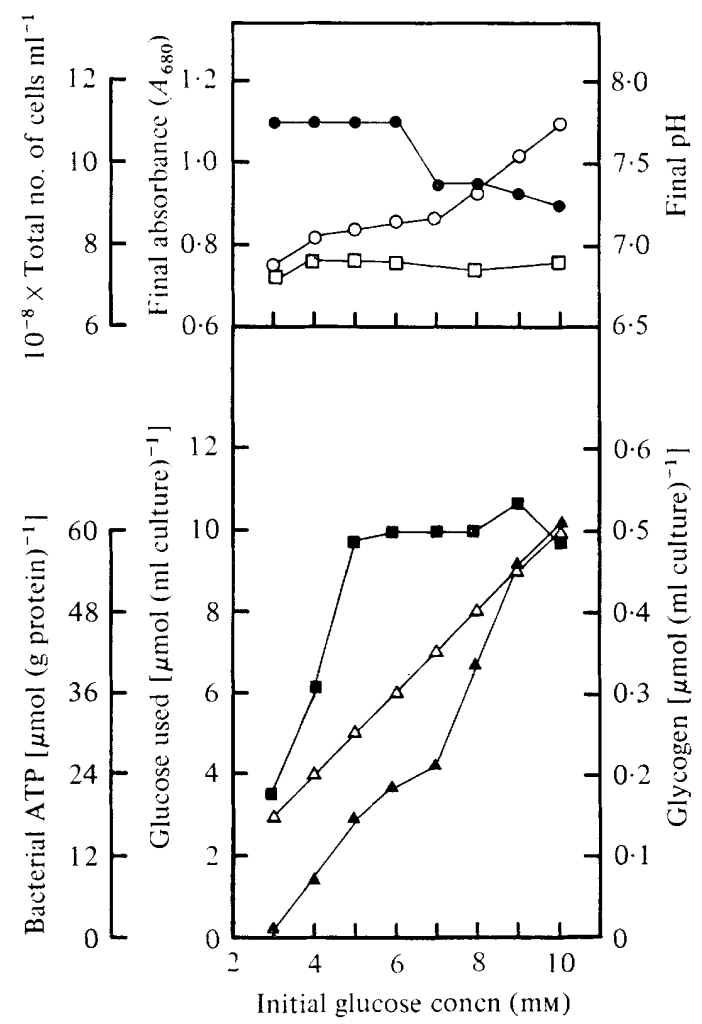

Fig. 3. Effect of variation of initial glucose concentration in the medium on the maximum ATP pool size and glycogen content in the stationary phase. The initial ammonium concentration was $2.5 \mathrm{~mm}$ and the initial glucose concentration was varied as indicated. Bacteria were grown until glucose disappeared from the medium and then the following parameters were measured: culture absorbance $(\bigcirc)$, medium pH $(\bullet)$, total cell numbers $(\square)$, bacterial ATP $(\boldsymbol{\square})$, glucose used $(\triangle)$, glycogen formed $(\mathbf{\Lambda})$.

$\mathrm{NH}_{4} \mathrm{Cl}$, growth was limited by depletion of nitrogen from the medium. About $4.5 \mathrm{~mm}-$ glucose remained in the medium at this time; it was oxidized during the first $6 \mathrm{~h}$ of the stationary phase (Fig. $2 a$ ). About $8 \%$ of the excess glucose was converted to glycogen during this period (Fig. $2 c$ ). No poly- $\beta$-hydroxybutyrate or polyphosphate was detected during the early-stationary phase. Accumulated organic acids were also oxidized during this period, during a second respiratory phase (not shown), as described by Niven et al. (1977a).

Total and viable cell numbers continued to increase, by about $50 \%$, after the maximum absorbance had been reached (Fig. $2 b$ ). In contrast to carbon-limited cultures, there was only a gradual decrease in viability during starvation of nitrogen-limited cultures, with a viability of $30 \%$ at $50 \mathrm{~h}$ after inoculation (Fig. $2 \mathrm{~b}$ ). Total cell numbers remained relatively constant up to at least $90 \mathrm{~h}$, again indicating that loss of viability was not associated with cell lysis. The $\mathrm{pH}$ remained between $7 \cdot 2$ and $7 \cdot 5$ throughout the experiment.

The RNA content of the culture started to decrease immediately after growth had terminated, declining to about $50 \%$ of the maximum level at $50 \mathrm{~h}$ (Fig. $2 \mathrm{c}$ ). Surprisingly, the glycogen content of the cells did not start to decrease until $36 \mathrm{~h}$ after inoculation and was still $30 \%$ of the maximum level after $90 \mathrm{~h}$. The protein content of the cells decreased only slightly during the experiment (Fig. $2 a$ ).

During growth, the ATP content was $12 \mu$ mol (g protein) ${ }^{-1}$. The ATP pool then increased massively to about $60 \mu \mathrm{mol}$ (g protein) ${ }^{-1}$ at $10 \mathrm{~h}$ after inoculation (Fig. $2 d$ ). After 
a period of stability, the ATP content gradually decreased, although at $50 \mathrm{~h}$ it was still greater than the growth value. The energy charge was about 0.95 both during growth and in the stationary phase until approximately $22 \mathrm{~h}$ after inoculation. It then declined slowly to 0.65 at $90 \mathrm{~h}$, when both the viability and ATP content of the culture were extremely low.

A post-growth increase in adenylate content of nitrogen-limited cultures of $B$. natriegens has been reported previously by Niven et al. (1977a), but the initial glucose content of the cultures was $5 \mathrm{~mm}$ compared with $8 \mathrm{~mm}$ used in this study. The effect of variation of the initial glucose concentration on the maximum glycogen synthesis and adenylate content is shown in Fig. 3. With an initial $\mathrm{NH}_{4} \mathrm{Cl}$ concentration of $2.5 \mathrm{~mm}$, growth terminated due to carbon depletion from the medium when the initial glucose concentration was less than $3.5 \mathrm{~mm}$. At higher glucose concentrations, growth was terminated by nitrogen limitation. The maximum glycogen content increased with increasing initial concentration of glucose, up to $10 \mathrm{~mm}$. Of the glucose in excess of the requirement for growth, 6 to $8 \%$ was converted to glycogen at the start of the stationary phase. There was, however, an apparent maximum size of the adenine nucleotide pool, during the post-growth phase. At an initial glucose concentration of $6 \mathrm{~mm}$, equivalent to about $2.5 \mathrm{~mm}$ residual glucose at the start of the stationary phase, the maximum ATP content noted during the post-growth increase was $60 \mu \mathrm{mol}$ (g protein) ${ }^{-1}$. Further increases in initial glucose concentration did not result in higher concentrations of adenine nucleotides.

\section{DISCUSSION}

RNA was the preferred endogenous source of energy for maintenance of starving $B$. natriegens. The RNA content decreased progressively during starvation, whereas the protein content was relatively unaffected. It was only when the RNA content had decreased considerably, presumably to the minimum level essential for survival, that glycogen-rich cultures utilized glycogen to extend the period of viability. In glycogen-poor cultures, loss of viability occurred when the RNA content fell to about a third of the level found during growth.

Unlike E. coli (Chapman et al., 1971) and P. prévotii (Montague \& Dawes, 1974), loss of viability during starvation of $B$. natriegens was not associated with a decrease in energy charge below $0 \cdot 6$. No direct correlation was obtained between the size of the adenine nucleotide pool and loss of viability, although in both carbon- and nitrogen-limited cultures the ATP content decreased during starvation. The actual ATP pool in nitrogen-limited cultures was very much greater during starvation than that in carbon-limited cultures.

The viability of the $B$. natriegens cultures decreased during starvation without a decrease in the total cell numbers. This does not mean that the non-viable intact bacteria did not become permeable, losing some of their intracellular metabolites and proteins, etc., which could act as a source of nutrients for the remaining bacteria. No appreciable increase in absorbance at 260 or $280 \mathrm{~nm}$ was noted, nor were any extracellular adenylates found in the cell-free medium, but the remaining viable bacteria could have utilized these nutrients too rapidly for their detection. If this was occurring, it would explain the decrease in adenine nucleotide content of the culture and simultaneous maintenance of the energy charge at a value greater than 0.6 even when there had been a dramatic decrease in percentage viability.

The size of the adenylate pool is a balance between the rate of de novo synthesis of AMP plus the rate of salvage of AMP or its precursors from RNA catabolism and the rate of incorporation of ADP and ATP into RNA, DNA, proteins (in histidine residues) and cofactors (e.g. NAD) plus the rate of AMP catabolism (Knowles, 1979). At the start of the stationary phase there is a dramatic decrease in the demand for adenylate supply for synthesis of macromolecules. The rise in adenylate content of $B$. natriegens at the start of the stationary phase in the presence of glucose as an energy source, compared with the 
constant adenylate content of $E$. coli (Chapman et al., 1971), therefore reflects a difference in the overall regulation of the pathways in the two bacteria. The increase in size of the adenine nucleotide pool of $B$. natriegens occurred only as long as there was sufficient glucose present as an exogenous source of energy (Fig. 3).

An important difference between the organisms could be the pattern of AMP catabolism. Escherichia coli contains AMP nucleosidase and, as a periplasmic enzyme involved in adenosine uptake, AMP nucleotidase (Schramm \& Lazorik, 1975; Yagil \& Beacham, 1975 ). Indirect assays on cell-free extracts of $B$. natriegens suggested the presence of AMP deaminase and AMP nucleotidase (Niven et al., 1977b). However, further attempts to detect and purify the former enzyme have been unsuccessful (M. A. Pickard, P. A. Collins \& C. J. Knowles, unpublished observations). The ability of intact cells of $B$. natriegens to degrade exogenous AMP (M. A. Pickard, personal communication) and to utilize AMP as a carbon source (Niven et al., 1977a) suggests that AMP nucleotidase may be periplasmic in this bacterium. Beneckea natriegens does not form AMP nucleosidase.

In Azotobacter vinelandii, AMP nucleosidase is activated by a decrease in energy charge, and its role may be to buffer energy charge at the expense of the total adenine nucleotide pool size under conditions where the cell is unable to regenerate ATP from ADP sufficiently rapidly (Schramm \& Leung, 1973). If the AMP nucleosidase of E. coli is regulated in a similar manner, the enzyme would not be active under the energy-rich conditions prevailing at the start of the stationary phase in the presence of excess glucose. Thus, the difference in maintenance of the size of the adenine nucleotide pools of $B$. natriegens and $E$. coli could not be explained by the presence of this enzyme in the latter organism only.

On the other hand, when growth stops due to carbon-limitation the drop in energy charge of $E$. coli could activate AMP nucleosidase, thus accounting for the decrease in adenine nucleotide pool size under these conditions (Chapman et al., 1971; WalkerSimmons \& Atkinson, 1977; Andersen \& von Meyenburg, 1977). In B. natriegens, which does not form this enzyme, there was no drop in adenine nucleotides on carbon-limitation.

The increase in adenine nucleotide content at the start of the stationary phase of nitrogenlimited cultures of $B$. natriegens was not associated with a measurable decrease in the RNA content. However, the RNA content was much greater than the adenine nucleotide content and only a small change in RNA concentration, which could not be accurately measured, would significantly alter the size of the adenylate pool. Consequently, it is not possible to conclude whether the extra adenylates are derived from salvage from RNA degradation or are due to de novo synthesis of AMP occurring at a greater rate than the decreased demand for RNA, DNA and protein synthesis.

Conversely, the decrease in RNA content as starvation progresses would lead to a dramatic increase in adenine nucleotide content unless the adenosine residues were further catabolized, with the other nucleoside residues, as a source of energy. The concomitant decrease in adenylate content of the cultures strongly suggests that this was occurring.

This work was supported by a grant from the Science Research Council. We wish to thank Dr M. A. Pickard for helpful discussions.

\section{REFERENCES}

Andersen, K. B. \& von MeyenburG, K. (1977). Changes of nicotinamide adenine nucleotides and adenylate energy charge as regulatory parameters of the metabolism of Escherichia coli. Journal of Biological Chemistry 252, 4151-4156.

AtKinson, D. E. (1968). The energy charge of the adenylate pool as a regulatory parameter. Interaction with feedback modifiers. Biochemistry 7 , $4030-4034$.
Atkinson, D. E. (1978). Cellular Energy Metabolism and its Regulation. London: Academic Press.

Baumann, P., Baumann, L. \& Mandel, M. (1971). Taxonomy of marine bacteria : the genus Boneckea. Journal of Bacteriology 107, 268-294.

Blobel, G. \& Potter, Van-R. (1968). Distribution of radioactivity between the acid-soluble pool and pools of RNA in the nuclear, non-sedimentable and ribosome fractions of rat liver after a single 
injection of labelled orotic acid. Biochimica et biophysica acta $166,48-57$.

Carter, I. S. \& Dawes, E. A. (1979). Effect of oxygen concentration and growth rate on glucose metabolism, poly- $\beta$-hydroxybutyrate biosynthesis and respiration of Azotobacter vinelandii. Journal of General Microbiology 110, 393-400.

Chapman, A. G. \& Atkinson, D. E. (1977). Adenine nucleotide concentrations and turnover rates. Their correlation with biological activity in bacteria and yeast. Advances in Microbial Physiology 15, 253-306.

Chapman, A. G., Fall, L. \& Atkinson, D. E. (1971). Adenylate energy charge in Escherichia coli during growth and starvation. Journal of Bacteriology 108, 1072-1086.

DAwEs, E. A. (1976). Endogenous metabolism and the survival of starved prokaryotes. Symposia of the Society for General Microbiology 26, 19-53.

Dawes, E. A. \& Senior, P. J. (1973). The role and regulation of energy reserve polymers in microorganisms. Advances in Microbial Physiology 10, $136-266$.

Dietzler, D. N., Lais, C. J. \& LeCKie, M. P. (1974). Simultaneous increases of the adenylate energy charge and the rate of glycogen synthesis in nitrogen-starved Escherichia coli W4597(K). Archives of Biochemistry and Biophysics 160, 1425.

Fiske, C. H. \& SubBarow, Y. (1925). The colorimetric determination of phosphorus. Journal of Bacteriology 66, 375-400.

Hassid, W. Z. \& Abraham, S. (1957). Chemical procedures for analysis of polysaccharides. Methods in Enzymology 3, 34-50.

Herbert, D., Phipps, P. J. \& Strange, R. E. (1971). Chemical analysis of microbial cells. Methods in Microbiology 5B, 209-344.

KNowles, C. J. (1977). Microbial metabolic regulation by adenine nucleotide pools. Symposia of the Society for General Microbiology 27, 241-283.

KNowles, C. J. (1979). Adenine nucleotide pool maintenance during bacterial growth and starvation. In Covalent and Non-Covalent Modulation of Protein Function, (in the Press). Edited by D. E. Atkinson.
Mallette, M. F. (1969). Evaluation of growth by physical and chemical means. Methods in Microbiology 1, 521-566.

Montague, M. D. \& Dawes, E. A. (1974). The survival of Peptococcus prévotii in relation to the adenylate energy charge. Journal of General Microbiology 80, 291-299.

Niven, D. F., Collins, P. A. \& Knowles, C. J. $(1977 a)$. Adenylate energy charge during batch culture of Beneckea natriegens. Journal of General Microbiology 98, 95-108.

Niven, D. F., Collins, P. A. \& Knowles, C. J. $(1977 b)$. Catabolism of adenosine 5 -monophosphate by extracts of the marine bacterium Beneckea natriegens. Journal of General Microbiology 100, 5-13.

Poole, R. K. \& Salmon, I. (1978). The pool sizes of adenine nucleotides in exponentially growing, stationary phase and 2'-deoxyadenosine-synchronized cultures of Schizosaccharomyces pombe $972 \mathrm{~h}^{-}$. Journal of General Microbiology 106, 153-164.

Postgate, J. R., Crumpton, J. E. \& Hunter, J. R. (1961). The measurement of bacterial viabilities by slide culture. Journal of General Microbiology 24, 15-24.

Schramm, V. L. \& Lazorik, F. C. (1975). The pathway of adenylate catabolism in Azotobacter vinelandii. Evidence for adenosine monophosphate nucleosidase as the regulatory enzyme. Journal of Biological Chemistry 250, 1801-1808.

Schramm, V. L. \& LeUNG, H. (1973). Regulation of adenosine monophosphate levels as a function of adenosine triphosphate and inorganic phosphate. A proposed metabolic role for adenosine monophosphate nucleosidase from Azotobacter vinelandii. Journal of Biological Chemistry 248, 8313-8315.

Walker-Simmons, M. \& Atkinson, D. E. (1977). Functional capacities and the adenylate energy charge in Escherichia coli under conditions of nutritional stress. Journal of Bacteriology 130, 676-683.

YAGIL, E. \& BEACHAM, I. R. (1975). Uptake of adenosine 5 '-monophosphate by Escherichia coli. Journal of Bacteriology 121, 401-405. 